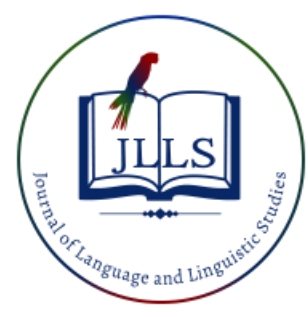

Available online at www.jlls.org

JOURNAL OF LANGUAGE

AND LINGUISTIC STUDIES

ISSN: 1305-578X

Journal of Language and Linguistic Studies, 17(2), 924-940; 2021

\title{
Self-efficacy sources and reading comprehension of L2 undergraduate learners
}

\author{
Mohammed Abdullah Alharbi ${ }^{\text {a } 1}$ iD \\ APA Citation: \\ ${ }^{a}$ Majmaah University, Majmaah, Saudi Arabia \\ Alharbi, M.A. (2021). Self-efficacy sources and reading comprehension of L2 undergraduate learners. Journal of Language and Linguistic \\ Studies, 17(2), 924-940. Doi: 10.52462/j1ls.64 \\ Submission Date: 18/02/2021 \\ Acceptance Date:05/05/2021
}

\begin{abstract}
In EFL context of higher education, reading comprehension is considered one of the most indispensable skills to learn. The aim of the present was to explores the perceptions of learners of English as a foreign language (EFL) with regard to the role of Bandura's four hypothesized sources for reading self-efficacy in reading comprehension. A qualitative research methodology was implemented to realize the study's objective. In total, six EFL learners were selected from six public Saudi universities using homogeneous purposeful sampling over one academic semester. A semi-structured interview protocol was developed to collect the data, and thematic analysis was employed. The findings revealed several factors that influence the effectiveness of the different self-efficacy sources on reading comprehension, such as the role of teachers, the competitive environment, confidence, and time constraints, etc. These findings underlie useful implications for teaching and learning reading comprehension in an EFL context. The study offers several theoretical and practical implications for EFL learners, instructors, and educational policymakers to assist in enhancing self-efficacy beliefs among learners to facilitate their English reading comprehension.
\end{abstract}

Keywords: self-efficacy sources; reading comprehension; qualitative inquiry; L2 reading; reading skills

\section{Introduction}

Academic achievement largely depends on students' reading comprehension skills (Grabe, 1991). Moreover, int the context of higher education, reading comprehension is considered one of the most indispensable skills (Meniado, 2016). It is essential for students to comprehend what they read, in order to navigate subject-related demands at the university level (Meniado, 2016). Regrettably, the International English Language Testing System (IELTS) (2017) report revealed extremely low reading scores among students from some English as foreign language (EFL) countries, including the Kingdom of Saudi Arabia (KSA). More specifically, of the nine IELTS bands, the average band results acquired by Saudi students in reading skills were 5.05 (i.e. the third-lowest in the world) and 3.90 (i.e. the lowest in the world) in the academic and general IELTS categories respectively. Moreover, from a global perspective, previous research has indicated that EFL students encounter significant hurdles with reading comprehension (Al Seyabi \& Tuzlukova, 2015 in Oman; Chen \& Chen, 2015 in Taiwan; Cho \& Brutt-Griffer, 2015 in South Korea; Guimba \& Alico, 2015 in the

\footnotetext{
1 Corresponding author.

E-mail address: maalharbi@mu.edu.sa
} 
Philippines; Hamra \& Syatriana, 2015 in Indonesia). Moreover, in the context of KSA, researchers have revealed that when students enter university level after completing their school education, their reading comprehension level is relatively poor (Al-Qahtani, 2016; Meniado, 2016, Shehzad, Lashari, Alghorbany, \& Lashari, 2019).

Research indicates that readers persist with reading tasks if they have faith in their capability to comprehend texts effectively (Unrau et al., 2018). It has been established in 'social cognitive theory (SCT) that learners' opinions regarding their own capacity to accomplish a task play a significant role in their achievements or failures (Bandura, 1986). Self-efficacy beliefs instill motivation in people, enabling them to achieve success in every walk of life (Bandura, 1986, 1997). In the context of reading comprehension, the construct of self-efficacy demands attention in KSA. In the context of KSA, only a few researchers have conducted studies to investigate the relationship between the different types of self-efficacy (i.e. general self-efficacy, English self-efficacy, social self-efficacy, and foreign language self-efficacy) and various associated achievements (i.e. academic achievement, language achievement, oral achievement) (Al-Hebaish \& Mohammad, 2012; Al-Roomy, 2015; Humaida, 2017; Koura \& Al-Hebaishi, 2014; Razek \& Coyner, 2014; Saleem, Ali, \& Ab Rashid, 2018). At the time of writing, there is a severe dearth of studies related to 'reading self-efficacy' (Shehzad et al., 2019).

This paper used the self-efficacy framework proposed by Bandura (1986), which affirmed that selfefficacy beliefs originate from four sources, including 'mastery experience', 'vicarious experience', 'verbal persuasion,' and 'physiological state'. 'Mastery experience' includes an individual's past experiences of success and failure. It is considered as the most influential as compared to the other three sources (Bandura, 1986, 1997). Self-efficacy beliefs are boosted by successes but lowered when one suffers failures. The second source of self-efficacy beliefs, observations of other individuals' experiences, particularly those of one's peers (vicarious experience). In other words, one can observe successful peers and be persuaded that it is possible to accomplish similar tasks. 'Verbal persuasion' is identified as the third source of self-efficacy and refers to feedback from significant people in the individual's life, i.e. parents, peers, and teachers. The feedback can influence individual performance. Finally, the fourth self-efficacy source, i.e. 'physiological state' refers to anxiety and exhaustion, which can affect one's self-efficacy beliefs (Bandura, 1986). These four hypothesized sources of self-efficacy are responsible for the self-efficacy an individual holds, and inform their performance (Bandura, 1986, 1997). In prior literature, researchers have observed the relationship between self-efficacy sources and various academic variables, including mathematics achievement and English language achievement (Usher, 2009; Usher \& Pajares, 2009). However, there is a scarcity of research targeting the relationship between self-efficacy sources and English reading comprehension. In fact, just one (quantitative) research study investigating the relationship between self-efficacy sources and reading comprehension (i.e. Shehzad et al., 2019) was found when preparing this article. In order to gain a more robust insight into the aforementioned variables, it is vital to conduct research using a qualitative approach. Therefore, this study aimed to explore EFL learners' perspectives regarding the influence of self-efficacy sources on their reading comprehension

\section{Literature review}

\subsection{Self-efficacy Beliefs and Self-efficacy Sources}

Previous studies have established the connection between self-efficacy sources and self-efficacy beliefs in various domains. For instance, several researchers have determined the relationship between two variables in the science domain (Chen \& Usher, 2013; Lin \& Tsai, 2018). Both studies revealed a substantial connection between self-efficacy sources and science self-efficacy beliefs. Additionally, 
several researchers have conducted studies regarding the association between these two variables in the domain of mathematics (Phan, 2012; Usher \& Pajares, 2009). The remainder of the researchers conducted studies examining self-efficacy sources in several domains including learning, English language, teaching, and writing (Arslan, 2012; Lin, 2016; Phan \& Ngu, 2016; Tschannen-Moran \& McMaster, 2009). The majority of the aforementioned studies concluded that there exists a significant connection between self-efficacy sources and self-efficacy beliefs.

Reflecting on the studies reviewed above, it is noteworthy that the majority of studies have focused on science and mathematics self-efficacy sources. A dearth of research regarding the connection between reading self-efficacy sources and reading self-efficacy beliefs was revealed (Shehzad, Hamzah, \& Rawian, 2018). According to Cantrell et al. (2013) research needs to be conducted to identify the association between self-efficacy sources and reading self-efficacy beliefs, which will consequently enrich insights regarding the self-efficacy construct.

The current section has reviewed studies linking self-efficacy sources with various academic variables. The next section reviews studies of the association between self-efficacy beliefs and reading comprehension

\subsection{Self-efficacy Beliefs and Reading Comprehension}

Several studies have been piloted to examine the connection between self-efficacy beliefs and reading comprehension, the majority using primary school students as their study participants (Aro et al., 2018; Carroll \& Fox, 2017; Lee \& Jonson-Reid, 2016; Wilson \& Kim, 2016). Almost all the aforementioned studies found a significant association between the two variables. Only two studies (i.e. Carroll \& Fox, 2017; Wilson \& Kim, 2016) uncovered an insignificant relationship between selfefficacy and reading comprehension.

Furthermore, numerous studies were conducted with high school students (Booth et al., 2017; Hedges \& Gable, 2016; Osman et al., 2016; Schöber, Schütte, Köller, McElvany, \& Gebauer, 2018). The above-mentioned studies found a significant association between self-efficacy beliefs and reading comprehension, except for a study by Booth et al. (2017), which reported an insignificant relationship.

In addition, various studies have been conducted in a university setting (Oh, 2016; Shang, 2010; Shehzad et al., 2019; Tabrizi \& Jafari, 2015; Yoğurtçu, 2013), and have revealed a significant connection between self-efficacy and reading comprehension, with the exception of Yoğurtçu's (2013) study. Yoğurtçu (2013) discovered that reading comprehension self-efficacy was associated with reading comprehension skills for high self-efficacious students. However, for low self-efficacious students, there was no significant relationship observed between the two variables.

\section{Method}

\subsection{Research design}

The current study employed a qualitative research approach, due to the nature of the research objective. A qualitative research approach is preferred over a quantitative approach, as it gives the researcher an opportunity to examine phenomena from a broader and in-depth perspective (Hammersley, 2000). For instance, with respect to the present study, when conducting interviews, EFL learners' perspectives regarding the influence of self-efficacy sources on reading comprehension were obtained more effectively. 


\subsection{Sampling}

To achieve this objective, homogeneous purposeful sampling was used to select a qualitative sample as suggested by Creswell (2003). Homogeneous purposeful sampling is appropriate for studies searching for participants having similar attributes (Creswell, 2003). Creswell (2003) further suggests that a researcher needs to identify the particular attributes that he/she is looking for in the target population. In the context of the current research, the researcher looked for three principal attributes. Firstly, that the gender of the sample ought to be male. Secondly, the sample should be gathered from public universities only. Finally, the sample should be gathered from a Preparatory-Year-Programme (PYP). As far as the sample size is concerned, the researcher followed the guidelines proposed by Kuzel (1992). He suggested a sample size of six to eight interviewees is appropriate for a homogeneous sample. Thus, six interviewees from six government universities were chosen as the current study was homogeneous in nature.

\subsection{Instrument}

In the current study, semi-structured interviews were employed to gather the qualitative data. In this type of interview, major questions and certain key topics are pre-selected before the interview, and the option is there to ask questions depending upon the responses of the interviewees (Kajornboon, 2005). The researcher developed the interview questions to achieve the current study's objective (refer to Appendix). There were seven major questions in the interview protocol and several sub-questions for each major question.

\section{Data analysis}

The current study employed a thematic analysis approach to analyze the data collected from the semi-structured interview protocol. The method employed in the current study for analyzing the qualitative data was adapted from Graneheim and Lundman (2004). They indicated four vital steps to extract themes from the data. In the first step, the researcher needs to get involved in the data, reading the transcripts repeatedly to detect substantial topic strands. These strands of data are then designated a meaning entity. The second step involved the extraction of meaning entities into plain and uncomplicated words or ideas, referred to be Graneheim and Lundman (2004) as 'condensed meaning units'. The third step included deduction from condensed meaning entities into advanced logical levels (Graneheim \& Lundman, 2004). The primary phase was defined as a 'code', which acted as a 'label' assigned to identify the condensed meaning entity (Thomas, 2003). The final step involved additional classification of the data codes (Graneheim \& Lundman, 2004). These codes were arranged based on cohesion, in order to generate subcategories, categories and ultimately themes (Thomas, 2003).

\section{Findings}

This section presents the findings related to four self-efficacy sources (i.e. mastery experience, vicarious experience, verbal persuasion, and physiological state) on EFL learners' reading comprehension.

\subsection{Influence of Mastery Experience on Reading Comprehension}

Mastery experience is the first source of self-efficacy. This section discusses the influence of both positive and negative mastery experiences on the reading comprehension of EFL learners. Firstly, the findings relating to positive mastery experiences are presented. Learners mentioned various factors associated with the positive mastery experience that could potentially influence their reading 
comprehension, including the role of reading strategies, the role of the reading teacher, and topics of interest.

S1, S4 and S6 considered the role of reading strategies successfully employed in the past as the main cause of improved reading comprehension. For instance, $\mathrm{S} 1$ employed the technique of rereading the text and considered it vital for improved reading comprehension:

...What I remember was like when I read, I read all the time like repeat, repeat.

That's what makes me improve in reading the passage. (S1)

S4 mentioned some of the reading strategies including skimming, scanning and using background knowledge to improve his reading comprehension.

Some of the respondents (i.e. S3, S4 \& S5) considered the role of their English reading teachers as another major factor adding to improvements in their current reading comprehension. For instance, S5 stated:

I remember in high school, there was a teacher of English and he worked a lot on my reading skills. He used to pay special attention to me regarding reading skills and vocabulary. (S5)

Lastly, S2 indicated that 'topics of interest' played a crucial role in improving his reading comprehension:

$Y e a$, actually when I took an exam three weeks ago, there was a passage about football. So, I did really well. Actually, I have an interest in football and if anything similar to that topic comes again, I will do well hopefully. (S2)

While sharing their views on positive mastery experiences, learners also disclosed various factors related to negative mastery experiences that could potentially influence their reading comprehension adversely, including poor vocabulary, lack of familiarity with the topic, a substandard school education system, and incompetent teachers.

Some respondents (i.e. S3 \& S4) shared that the substandard school education system was a potential reason for their poor reading comprehension. They identified problems such as late exposure to reading and poor methods employed when reading a text.

Yes, I remember when I was in high school. At that time I used to perform poorly in reading tasks... Also, I started studying reading English in sixth grade. You know, that's really late. (S3)

I think in high school I used to perform really badly in all the reading tests. I still remember we used to learn everything by heart and we had no understanding. (S4)

In some cases, the learners blamed their teachers directly for their poor reading comprehension.

...he (the teacher) didn't teach me well and he just used to waste time. He wasn't a good teacher actually. (S3)

Unlike S3, S6's viewpoint differed. S3 criticized his English teachers for their poor teaching skills with regard to reading. However, in the case of S6, the teacher had embarrassed him in front of the class, which had then affected his reading comprehension negatively.

I remember once in high school, I read a passage and made a lot of mistakes while reading. So, the teacher said, "Ok! Any other student who answers should read". At that time, I became nervous and embarrassed. So, whenever, I remember that, ...that affects my reading performance even now. (S6) 
Among many factors, another potential cause of the negative mastery experience influencing the reading comprehension of EFL learners was 'poor vocabulary knowledge'. S1 stated,

...Surely poor performance because of poor vocabulary and grammatical skills would lower my reading performance of today. (S1)

Additionally, EFL learners considered 'unfamiliarity with the topics' as a possible factor associated with negative mastery experience; one that influenced their reading comprehension negatively. S2 stated,

A few days back, I got the topic anthropology in the reading exam and I had no idea about it. So, how could I answer it when I didn't know about it, not even in Arabic. So, how could I answer in English? (S2)

\subsection{Influence of Vicarious Experience on Reading Comprehension}

Vicarious experience is the second source of self-efficacy. This section discusses the influence of both positive and negative vicarious experiences on the reading comprehension of EFL learners. Firstly, the findings regarding positive vicarious experiences are presented. Learners mentioned various factors associated with positive vicarious experiences that might influence reading comprehension, including motivation from peers, seeking help from peers and a competitive environment.

The EFL learners in the current study compared themselves with other learners who were good at reading and were then motivated by them. $\mathrm{S} 1$ shared his views as follows:

When I see someone performing well in reading, I ask myself- if he can do it, why can't I? (S1)

Moreover, some of the respondents sought their peers' help with reading after observing their good reading performances. S3 shared his views with regard to seeking help from his peers, as follows.

If I faced any difficulty with reading, I used to consult her (his sister) and she taught me really well and I understood her completely. Usually, if any of my classmates perform well in reading, I approach him and ask him what I don't know about reading. (S3)

In addition, the majority of the respondents (i.e. S1, S2, S4, \& S5) started working hard after observing their peers doing well in reading, and consequently, that created a competitive atmosphere between them. Thus, being in a 'competitive environment' was a factor related to the positive vicarious experience that influenced their reading comprehension. For instance, S5 stated:

Actually, when anybody performs well in reading... I would study hard and try to improve and develop myself in reading to be like him or close to him. (S5)

As EFL learners disclose their opinions on positive vicarious experience, correspondingly they share several factors regarding negative vicarious experiences that would potentially influence their reading comprehension; including, 'peer tutoring' and 'feelings of happiness at others' failures'.

Some learners (i.e. S2, S3, \& S4) felt sympathetic towards other learners who failed to perform well in reading and offered to teach reading skills to them, which consequently affected their own reading performance as well.

If he needs help, I can help him by teaching him the techniques needed to complete a reading comprehension test that I know. I will do a lot of preparation to teach him. So, in this way, my reading performance gets better too. (S4) 
Surprisingly, one of the respondents (i.e. S6) felt happy about their peers' bad reading performances as it led him to perform better in reading. This is known as 'Schadenfreude' i.e. 'feeling happy at another's failures'.

If I observe someone and he's not good at reading, I would feel happy because I would feel that I am better than him, and that would give me the motivation to perform even better in the reading exam. (S6).

\subsection{Influence of Verbal Persuasion on Reading Comprehension}

Verbal persuasion is the third source of self-efficacy. This section discusses the influence of both positive and negative verbal persuasion on the reading comprehension of EFL learners. Firstly, findings relating to positive verbal persuasion are presented. Two major factors were stated by the interviewees regarding the positive verbal persuasion that could potentially affect their reading comprehension performance, including 'getting confidence' and 'gaining happiness from positive feedback'.

S1, S2, S4, and S5 claimed that encouraging remarks from teachers or parents would increase their confidence in reading, and eventually, their reading comprehension improved. S5 shared[:]

My teachers here in PYP always praise me and that boosts my confidence level. (S5)

Moreover, S6 indicated that positive feedback from his teachers was a source of happiness for him. As a consequence of his happiness, his reading comprehension performance improved. S6 stated,

Yes, in the university, I hear a lot of good words or remarks from my teachers like,

"Yes, you are doing well"...I then feel happy. When I feel happy then I read well and I definitely like reading. (S6)

While sharing their views on positive verbal persuasion, learners also reveal numerous factors related to negative verbal persuasion that might influence their reading comprehension, including embarrassment, remaining absent from class and the negative effect on mental health.

S2 reported that if he received negative feedback from a teacher, then he would be very embarrassed in front of the class, sometimes to such an extent that he would absent himself from the next class. According to $\mathrm{S} 2$,

...I would be absent from the next class due to embarrassment if someone utters bad words to me, especially if he/she is one of my parents or a teacher... So, yea I won't be able to perform well in reading after such comments (S2)

S2 also indicated that negative comments could be detrimental to his mental and psychological health, which would consequently affect his reading comprehension performance. He stated,

That will affect my brain because I expect good words from them because when they say good words to me, I am a better man. So, yea I won't be able to perform well in reading after such comments $(S 2)$

\subsection{Influence of Physiological State on Reading Comprehension}

The physiological state is the fourth source of self-efficacy. There were several major factors reported by the interviewees pertaining to the influence of the physiological state on reading comprehension performance, including lack of time, difficulty with a passage, lack of preparation, skipping words, lack of focus, and fear of failure. 
Interestingly, several respondents (i.e. S1, S2, \& S4) revealed that one of the main reasons for becoming nervous in a reading comprehension exam was lack of time, which consequently affected their reading comprehension negatively. S1 stated:

Well, during a reading exam, I become nervous about whether I can answer these questions or not because I have not enough time (S1)

However, S5 and S6 provided different reasons for their nervousness while reading that they felt affected their reading performance. For S5, 'difficulty with the passage', and for S6, 'lack of preparation', were the main causes of nervousness.

When I read a passage [Pause], actually [Pause], if it's difficult or there is a difficult word, I actually feel nervous and can't answer the questions properly. (S5)

I feel nervous if I haven't prepared for the test, or when I don't know about the passage. For instance, if the teacher takes a sudden quiz then surely I would feel nervous and not perform well in my reading. (S6)

Other factors that might account for nervousness during reading are: skipping words, lack of focus, and fear of failure.

Sometimes when you are nervous, you skip words. For instance, if there is an 'S' at the end of a word, but you can't see it. So, you make mistakes like that. (S1)

When I am nervous, I can't answer the questions because I am unable to think properly. (S2)

If I am nervous then everything is going to be bad, really bad because I can't focus on the exam. I just [pause], something happens inside my mind, like I will fail this test, I will be expelled from the university, and go back home. (S4).

\section{Discussion}

In the coming sections, the findings of the current study regarding the roles of self-efficacy sources in reading comprehension are discussed in light of previous literature.

\subsection{Discussion of Findings Regarding Mastery Experience and Reading Comprehension}

The respondents revealed that 'usage of reading strategies was one of the chief factors affecting their reading comprehension positively. This factor was identified by two respondents (i.e. S1 \& S4). The respondents in the current study might have improved their reading comprehension because they were in the second semester of PYP, which focuses on teaching metacognitive reading strategies to assist learners to develop reading comprehension skills. Several studies concur with the findings reported here concerning the beneficial effect of reading strategies on reading comprehension (Alfangca \& Tamah, 2017; Mudra, 2018). Harvey and Goudris (2000) asserted that reading strategies are indispensable tools for effective comprehension, as they assist the reader in understanding written text.

'The role of a reading teacher' was also identified by three respondents (i.e. S3, S4, \& S5) as a means to improve their reading comprehension. This finding corresponds with numerous studies (Bryant, 2017; Taylor, Pearson, Clark and Walpole, 2000; Usher, 2009), which have affirmed that good teachers teach reading strategies resulting in better reading performance. The current finding could be attributed to several factors. Of particular note is that the respondents in the current study might have attended International schools. International schools in the KSA recruit native Englishspeaking teachers, who might have used an appropriate methodology to teach reading skills, ultimately 
benefitting the reading comprehension of EFL learners. Another point is that mentioned above, i.e. the respondents were studying in the second semester of the PYP at the time of data collection. They might have been taught by very good teachers in the first semester, thereby improving their reading comprehension.

Last but not the least, 'the role of topics of interest was reported as another factor enhancing the reading comprehension success of respondents. The role of topics of interest has been studied in previous studies, and the findings revealed that it is a vital predictor of reading comprehension achievement (Asgari, Ketabi, \& Amirian, 2017; Ebrahimi \& Javanbakht, 2015).

The findings associated with positive mastery experiences were discussed above. In the coming paragraphs, the findings revealing negative mastery experience are discussed below in light of previous literature.

The respondents identified the 'substandard school education system' as an important negative mastery experience that impeded their development of reading comprehension skills. This finding is supported by several prior studies, which have indicated that the reading proficiency level of school learners was poor after they had completed their school education (Alrabai, 2016; Rahman \& Alhaisoni, 2013). Several explanations have been offered in the previous literature regarding the role of the substandard school education system in the KSA in causing the poor reading comprehension performance of learners, including late exposure to English learning in schools (Mahboob \& Elyas, 2014), and the small amount of time apportioned to the subject of English in government schools (AlSadan, 2000), as well as the poor syllabus (Rahman and Alhaisoni, 2013).

The second factor related to negative mastery experience, which was found to have a negative impact on the reading comprehension of respondents was the 'incompetency of their English teachers'. In other words, the respondents believed that in their former academic careers, their teachers had not paid adequate attention to developing their reading skills, which impeded the development of their reading comprehension skills. This finding regarding incompetent English teachers in Saudi schools is supported by several past studies. These studies stated that Saudi school teachers have insufficient pedagogical knowledge, and the teaching methodology they adopt when teaching English is inappropriate (Alsaif \& Milton, 2012; Fareh, 2010).

In addition, it was also revealed that learners' reading comprehension was negatively affected by their 'poor vocabulary'. The finding is supported by past studies (Al-Mahrooqi, 2012; Birch, 2014; Ruegg \& Naganuma, 2019), and could result from the learners' social environment. EFL learners use their mother tongue, i.e. Arabic in everyday life. Thus, due to the lack of exposure to the English language, they are unable to acquire English language vocabulary, which in turn affects their reading comprehension.

'Unfamiliarity with the topics' was identified as another factor associate with negative mastery experience that impacts reading comprehension negatively. This finding is supported by numerous past studies (Fareh, 2010; Horiba \& Fukaya, 2015). One possible reason for the current finding could be the lack of topics related to Saudi culture in their English syllabus. Fareh (2010) claimed that EFL Arab learners have to read English books as part of their syllabus, which causes them to lose interest, with the result that their comprehension is affected.

\subsection{Discussion of Findings Regarding Vicarious Experience and Reading Comprehension}

Regarding positive vicarious experiences, the first factor found to have a positive impact on reading comprehension was 'getting motivation from peers'. This finding is consistent with that in several past studies (Usher, 2009; Williams, 2017). A possible conjecture behind the current finding is that EFL learners enter PYP intending to pursue higher studies in prestigious institutions in Saudi 
Arabia. They are aiming not only to get a place in a higher education institution but also to be successful there, which requires good reading comprehension. Therefore, individuals gain motivation from each other's good reading performances, which consequently improves their own.

Regarding positive vicarious experience, the respondents identified another factor (i.e. seeking help from peers) as having a positive impact on reading comprehension. In other words, when learners observe their peers in positive or successful reading performance, they seek help from them in order to improve their own reading comprehension. Other qualitative studies have also found that learners seek help from their peers to improve their performance (Usher, 2009; Williams, 2017). This finding could be attributed to the students' culture. Saudi culture is based on brotherhood and fraternity, and people do not feel hesitant about seeking help. Therefore, this factor could be one of the potential reasons for improvements in the participants' reading comprehension.

Regarding positive vicarious experience, another factor with a positive influence on reading comprehension was the development of a 'competitive environment among learners'. The learners shared that whenever they observed their peers performing well in reading, they started working harder to improve themselves. This finding corresponds with that reported previously in the literature (Burguillo, 2010; Usher, 2009). In contrast, Ames and Ames (1984) believed that when learners work freely in the absence of a competitive environment, they focus more on developing competence and task mastery.

The findings relating to positive vicarious experience were discussed above. In the coming paragraphs, findings with regard to negative vicarious experience are discussed in light of previous relevant literature.

Regarding negative vicarious experience, the first factor found to have a positive influence on reading comprehension was 'peer tutoring'. In other words, the respondents claimed that whenever they observed someone in their class performing badly in the context of reading comprehension, they felt sympathetic towards them and offered them their assistance, which consequently improved their own reading comprehension performance. Previous literature also indicated that peer tutoring positively affects one's own performance (Veletsianos \& Russell, 2014). This finding can also be attributed to the Saudi culture of helping others. The whole of society is woven together due to cultural and religious factors, and so the respondents of the current study found it natural to teach their reading comprehension skills to their peers, thereby improving their own reading comprehension as a consequence of the extra study.

Another factor related to negative vicarious experience, that influenced the reading comprehension of the respondents was 'schadenfreude'. In the previous literature, some studies had identified this factor (Usher, 2009; Williams, 2017). Schadenfreude is very much associated with envy, and occurs when an individual observes someone who is advantaged or fortunate facing a misfortune (Heider, 2013). Thus, in the current study's context, some of the EFL learners felt happy about one another's failures in reading, because those learners who faced failure were advantaged and fortunate in terms of reading.

\subsection{Discussion of Findings Regarding Verbal Persuasion and Reading Comprehension}

Regarding positive verbal persuasion, the first factor found to have a positive impact on reading comprehension was 'getting confidence'. S1, S2, S4, S5 and S6 affirmed that good remarks from teachers or parents increased their confidence in reading and ultimately their reading comprehension improved. This finding is in line with several past studies, which indicated that positive feedback was a source of confidence for them(Fong \& Krause, 2014; Usher, 2009). This finding could be due to the PYP teachers might treating their students professionally. The majority of the PYP teachers are highly 
qualified and professionally trained. It is part of their training to encourage their students to build their confidence, which consequently improves the reading comprehension performance of their students.

Regarding positive verbal persuasion, the respondents identified another factor (i.e. happiness), as having a positive impact on their reading comprehension. In other words, respondents indicated that whenever they received positive feedback from their teachers related to reading, they became happy, and consequently, their reading comprehension improved. The current finding could be attributed to the lively and activity-based environment of PYP. In an activity-based environment, the teacher involves the students in different reading comprehension tasks and constantly provides feedback. This feedback plays a vital role in EFL learners' happiness, and consequently, they perform better in reading comprehension tasks. This finding is consistent with the previous literature (Achor, 2011; Mahfoodh \& Pandian, 2011).

The findings of positive verbal persuasion were discussed above. In the subsequent paragraphs, findings with regard to negative verbal persuasion are discussed in light of previous literature.

Regarding negative verbal persuasion, the first factor found to have a positive impact on reading comprehension was 'embarrassment'. That is, the respondents indicated that on occasion their teachers embarrassed them in front of classmates, and that affected their reading comprehension performance negatively. This finding corresponds to that reported by Ashcraft and Moore (2009). The respondents might have felt embarrassed when reading aloud in front of peers and teachers. It might also be possible that the teacher had corrected the respondents directly. According to universal pedagogical principles, the teacher should ideally correct the students' mistakes indirectly where possible to minimize their embarrassment (Teba, 2017).

Regarding negative verbal persuasion, the respondents identified another factor (i.e. remaining absent from class) as having a negative impact on their reading comprehension. The respondents mentioned this particular factor in relation to having faced negative feedback from teachers in previous classes and fearing being in such an uncomfortable situation again. The current finding agrees with that in previous literature (Frey \& Fisher, 2008).

Finally, with regard to negative verbal persuasion, the respondents identified the implications of criticism for their mental health when discussing factors that have a negative impact on their reading comprehension. This finding has been supported by several researchers in the literature (Frey \& Fisher, 2008; Kidger, Araya, Donovan \& Gunnell, 2012). Thus, from the above-mentioned literature, it is concluded that emotional health plays an important role in the reading comprehension performance of EFL learners. Therefore, teachers should create a conducive atmosphere based on positive reinforcement when giving learners feedback. When experiencing positive feedback, EFL learners are more likely to participate in reading activities with confidence and ultimately to perform better overall.

\subsection{Discussion of Findings Regarding Physiological State and Reading Comprehension}

Regarding physiological state, the first factor found to have a negative impact on reading comprehension was 'lack of time'. In other words, the respondents indicated that they were not given enough time by their teachers to attempt reading comprehension exercises, which consequently resulted in a lack of understanding of the texts. The probable reason for this finding could be anxiety. They might have become anxious due to a shortage of time, and consequently unable to concentrate on reading passages. This finding is supported in previous studies Aydin (2007).

'Lack of preparation' was further identified as another factor negatively affecting the reading comprehension of EFL learners. In other words, the learners reported that lack of preparation for reading exams provoked anxiety, and consequently this anxiety affected their reading comprehension. 
The current finding is consistent with findings reported by Bonaccio, Reeve, and Winford (2012). The possible reason for the lack of preparation for reading comprehension exams could be due to the fact that EFL learners have numerous other subjects to focus on, e.g. Mathematics, Science, etc. Thus, they might have not enough time left to prepare for a reading comprehension exam. As a consequence of this lack of preparation, their reading comprehension might be affected negatively.

Regarding physiological state, the respondents identified another factor (i.e. difficulty with passages), which had a negative impact on their reading comprehension. The probable reason behind this factor could be that PYP teachers prepare for difficult reading comprehension exams, due to the competitive nature of the program. They might want to differentiate between good and poor readers, as poor readers could encounter problems understanding difficult passages. The present finding is consistent with Usher's (2009) findings.

'Fear of failure' was identified as another factor influencing the reading comprehension of EFL students negatively. A plausible reason for this finding could be parents' expectations that they perform well. They might have overthought their parents' expectations, which might have resulted in anxiety, consequently affecting their reading comprehension negatively. This finding is consistent with numerous studies (Bandura, 1997; Fong \& Krause, 2014; Usher, 2009).

Finally, concerning the physiological state, the respondents identified a factor (i.e. lack of focus while reading) as having a negative impact on their reading comprehension. The respondents' lack of focus in reading could be attributed to the sleep patterns of the younger members of the population. As a consequence, when they perform reading comprehension activities in class or an exam, they cannot concentrate on the text properly, and their comprehension becomes affected. Another possible issue could be excessive usage of mobile phones when reading in the classroom. Their attention becomes diverted towards their mobile phones and consequently, their comprehension is then adversely affected. Usher (2009) maintained that lack of concentration is one of the most significant reasons for poor reading comprehension.

\section{Conclusion}

The findings of this study afford several theoretical and practical implications. In the current study, the perceptions of EFL learners regarding the role of 'self-efficacy sources' in 'reading comprehension' were obtained using a qualitative approach. Previously, only one study, i.e. Shehzad et al. (2019) has determined the association between the aforementioned variables using a quantitative approach. Therefore, the current study added valuable insights into the body of the literature through a qualitative lens. The findings of the study indicated several factors as being responsible for the potential role of self-efficacy sources in the reading comprehension of EFL learners. These findings could be equally beneficial for EFL teachers, students, and policymakers. EFL teachers can incorporate the self-efficacy sources of their students to improve their reading comprehension. Moreover, this study contributed to 'social cognitive theory (SCT). SCT has been used in numerous research fields. However, more specifically in EFL, the current research is the first of its kind to employ SCT to explore learners' perceptions regarding the role of 'self-efficacy sources' in 'reading comprehension. Thus, the current study has helped enlarge the scope of SCT.

\section{References}

Achor, S. (2011). The happiness advantage: The seven principles of positive psychology that fuel success and performance at work. New York, NY: Random House. 
Al Seyabi, F., \& Tuzlukova, V. (2015). Investigating EFL reading problems and strategies in postbasic schools and university foundation programmes: A study in the Omani context. Malaysian Journal of ELT Research, 11(2), 35-51.

Alfangca, K. Z., \& Tamah, M. S. M. (2017). The correlation between metacognitive reading strategies and reading comprehension of English department students. Magister Scientiae, 2(42), 135-142.

Al-Hebaish, S. M., \& Mohammad, S. (2012). The correlation between general self-confidence and academic achievement in the oral presentation course. Theory and Practice in Language Studies, $2(1), 60-65$.

Al-Mahrooqi, R. (2012). Reading literature in English: Challenges facing Omani college students. Asian EFL Journal, 57(1), 24-51.

Al-Qahtani, A. A. (2016). Why do Saudi EFL readers exhibit poor reading abilities? English Language and Literature Studies, 6(1), 1-15. http://dx.doi.org/10.5539/ells.v6n1p1

Alrabai, F. (2016). Factors underlying low achievement of Saudi EFL learners. International Journal of English Linguistics, 6(3), 21-37.

Al-Roomy, M. (2015). Evaluating Saudi university students' beliefs about learning English. International Journal of English Linguistics, 5(1), 22-31. http://dx.doi.org/10.5539/ijel.v5n1p22

Al-Sadan, I.A. (2000). Educational assessment in Saudi Arabian schools. Assessment in Education: Principles, Policy \& Practice 7(1), 143-155.

Alsaif, A., \& Milton, J. (2012). Vocabulary input from school textbooks as a potential contributor to the small vocabulary uptake gained by English as a foreign language learners in Saudi Arabia. The Language Learning Journal, 40(1), 21-33.

Ames, C., \& Ames, R. (1984). Goal structures and motivation. Elementary School Journal, 85(1), 3950 .

Aro, T., Viholainen, H., Koponen, T., Peura, P., Räikkönen, E., Salmi, P., \& Aro, M. (2018). Can reading fluency and self-efficacy of reading fluency be enhanced with an intervention targeting the sources of self-efficacy? Learning and Individual Differences, 67(1), 53-66. https://doi.org/10.1016/j.lindif.2018.06.009

Arslan, A. (2012). Predictive power of the sources of primary school students' self-efficacy beliefs on their self-efficacy beliefs for learning and performance. Educational Sciences: Theory and Practice, 12(3), 1915-1920.

Asgari, M., Ketabi, S., \& Amirian, Z. (2017). The Effect of Using Interest-based Materials on EFL Learners' Performance in Reading: Focusing on Gender Differences. Iranian Journal of English for Academic Purposes, 6(2), 1-12.

Ashcraft, M. H., \& Moore, A. M. (2009). Mathematics anxiety and the affective drop in performance. Journal of Psychoeducational Assessment, 27(3), 197-205.

Aydin, S. (2007). How can teachers reduce test anxiety of L2 learners? Humanising Language Teaching, 9(4), 1-3.

Bandura, A. (1986). The explanatory and predictive scope of self-efficacy theory. Journal of Social and Clinical Psychology, 4(3), 359-373. https://doi.org/10.1521/jscp.1986.4.3.359

Bandura, A. (1997). Self-efficacy: The exercise of control. New York, NY: Freeman. 
Birch, B. M. (2014). English L2 reading: Getting to the bottom. Abingdon, UK: Routledge.

Bonaccio, S., Reeve, C. L., \& Winford, E. C. (2012). Text anxiety on cognitive ability test can result in differential predictive validity of academic performance. Personality and Individual Differences, 52(4), 497-502.

Booth, M. Z., Abercrombie, S., \& Frey, C. J. (2017). Contradictions of adolescent self-construal: Examining the interaction of ethnic identity, self-efficacy and academic achievement. Mid-Western Educational Researcher, 29(1), 3-19.

Bryant, S. K. (2017). Self-Efficacy Sources and Academic Motivation: A Qualitative Study of 10th Graders (Doctoral dissertation). East Tennessee State University, Johnson City, United States of America.

Burguillo, J. C. (2010). Using game theory and competition-based learning to stimulate student motivation and performance. Computers \& Education, 55(2), 566-575.

Cantrell, S. C., Correll, P., Clouse, J., Creech, K., Bridges, S., \& Owens, D. (2013). Patterns of selfefficacy among college students in developmental reading. Journal of College Reading and Learning, 44(1), 8-34. https://doi.org/10.1080/10790195.2013.10850370

Carroll, J. M., \& Fox, A. C. (2017). Reading self-efficacy predicts word reading but not comprehension in both girls and boys. Frontiers in Psychology, 7(1), 2056. https://doi.org/10.3389/fpsyg.2016.02056

Chen, J. A., \& Usher, E. L. (2013). Profiles of the sources of science self-efficacy. Learning and Individual Differences, 24(1), 11-21. https://doi.org/10.1016/j.lindif.2012.11.002

Chen, K. T. C., \& Chen, S. C. L. (2015). The use of EFL reading strategies among high school students in Taiwan. The Reading Matrix: An International Online Journal, 15(2), 156-166.

Cho, H., \& Brutt-Griffler, J. (2015). Integrated reading and writing: A case of Korean English language learners. Reading in a Foreign Language, 27(2), 242-261.

Creswell, J. (2003). Research design: Qualitative, quantitative and mixed methods approaches ( $2^{\text {nd }}$ ed.). Thousand Oaks, CA: Sage.

Ebrahimi, S., \& Javanbakht, Z. (2015). The effect of topic interest on Iranian EFL learners' reading comprehension ability. Journal of Applied Linguistics and Language Research, 2 (6), 80-86.

Fareh, S. (2010). Challenges of teaching English in the Arab world: Why can't EFL programs deliver as expected? Procedia-Social and Behavioral Sciences, 2(2), 3600-3604.

Fong, C. J., \& Krause, J. M. (2014). Lost confidence and potential: a mixed methods study of underachieving college students' sources of self-efficacy. Social Psychology of Education, 17(2), 249-268. doi:10.1007/s11218-013-9239-1

Frey, N., \& Fisher, D. (2008). The under-appreciated role of humiliation in the middle school. Middle School Journal, 39(3), 4-12.

Grabe, W. (1991). Current developments in second language reading research. TESOL Quarterly, 25(3), 375-406. https://doi.org/10.2307/3586977

Graneheim, U. H., \& Lundman, B. (2004). Qualitative content analysis in nursing research: concepts, procedures and measures to achieve trustworthiness. Nurse Education Today, 24(2), 105-112.

Guimba, W. D., \& Alico, J. C. (2015). Reading anxiety and comprehension of grade 8 Filipino learners. International Journal of Humanities and Social Sciences, Special Volume, 44-59. 
Hammersley, M. (2000). The relevance of qualitative research. Oxford Review of Education, 26(3-4), 393-405.

Hamra, A., \& Syatriana, E. (2015). Developing a model of teaching reading comprehension for EFL students. TEFLIN Journal, 21(1), 27-40. http://dx.doi.org/10.15639/teflinjournal.v21i1/27-40

Harvey, S., \& Goudvis, A. (2013). Comprehension at the core. The Reading Teacher, 66(6), 432-439.

Hedges, J. L. and R. Gable. (2016). The relationship of reading motivation and self-efficacy to reading achievement.

Available

from:

http://scholarsarchive.jwu.edu/k12_ed/31/?utm_source=scholarsarchive.jwu.edu\%2Fk12_ed\%2F3

1

HYPERLINK

"http://scholarsarchive.jwu.edu/k12_ed/31/?utm_source=scholarsarchive.jwu.edu\%2Fk12_ed\%2F

31\&utm_medium=PDF\&utm_campaign=PDFCoverPages"\& HYPERLINK

"http://scholarsarchive.jwu.edu/k12_ed/31/?utm_source=scholarsarchive.jwu.edu\%2Fk12_ed\%2F

31\&utm medium=PDF\&utm campaign=PDFCoverPages"utm medium=PDF HYPERLINK "http://scholarsarchive.jwu.edu/k12 ed/31/?utm source=scholarsarchive.jwu.edu\%2Fk12 ed\%2F

31\&utm medium=PDF\&utm campaign=PDFCoverPages" \& HYPERLINK "http://scholarsarchive.jwu.edu/k12 ed/31/?utm source=scholarsarchive.jwu.edu\%2Fk12 ed\%2F 31\&utm medium=PDF\&utm campaign=PDFCoverPages"utm campaign=PDFCoverPages (accessed 26 March 2018).

Heider, F. (2013). The psychology of interpersonal relations. Hillsdale, NJ: Lawrence Erlbaum Associates.

Horiba, Y., \& Fukaya, K. (2015). Reading and learning from L2 text: Effects of reading goal, topic familiarity, and language proficiency. Reading in a Foreign Language, 27(1), 22-46.

Humaida, I. A. I. (2017). Self-efficacy, positive thinking, gender difference as predictors of academic achievement in Al-Jouf university students-Saudi Arabia. International Journal of Psychology and Behavioral Sciences, 7(6), 143-151. doi:10.5923/j.ijpbs.20170706.01

IELTS Partners (British Council, IDP: IELTS Australia Pty Ltd., and Cambridge English Language Assessment). (2017). IELTS Researchers: Test Taker Performance 2017. Retrieved December 17, 2017, from IELTS website: https://www.ielts.org/teaching-and-research/test-takerperformance 2017.aspx

Kajornboon, A. B. (2005). Using interviews as research instruments. E-journal for Research Teachers, 2(1), 1-9.

Kidger, J., Araya, R., Donovan, J., \& Gunnell, D. (2012). The effect of the school environment on the emotional health of adolescents: a systematic review. Pediatrics, 129 (5), 925-949.

Koura, A. A., \& Al-Hebaishi, S. M. (2014). The relationship between multiple intelligences, selfefficacy and academic achievement of Saudi gifted and regular intermediate students. Educational Research International, 3(1), 48-70.

Kuzel, A. 1992. Sampling in qualitative inquiry. In Doing qualitative research, ed. B. Crabtree and W. Miller, 31-44. Newbury Park, CA: Sage.

Lee, Y. S., \& Jonson-Reid, M. (2016). The role of self-efficacy in reading achievement of young children in urban schools. Child and Adolescent Social Work Journal,33(1), 79-89. doi: 10.1007/s10560-015-0404-6 
Li, Y., \& Wang, C. (2010). An empirical study of reading self-efficacy and the use of reading strategies in the Chinese EFL context. Asian EFL Journal, 12(2), 144-162.

Lin, G. Y. (2016). Self-efficacy beliefs and their sources in undergraduate computing disciplines: An examination of gender and persistence. Journal of Educational Computing Research, 53(4), 540561. https://doi.org/10.1177/0735633115608440

Lin, T. J., \& Tsai, C. C. (2018). Differentiating the sources of Taiwanese high school students' multidimensional science learning self-efficacy: An examination of gender differences. Research in Science Education, 48(3), 575-596.

Mahboob, A., \& Elyas, T. (2014). English in the kingdom of Saudi Arabia. World Englishes, 33(1), 128-142.

Mahfoodh, O. H. A., \& Pandian, A. (2011). A qualitative case study of EFL students' affective reactions to and perceptions of their teachers' written feedback. English Language Teaching, 4(3), $14-25$.

Meniado, J. C. (2016). Metacognitive reading strategies, motivation, and reading comprehension performance of Saudi EFL students. English Language Teaching, 9(3), 117-129. http://dx.doi.org/10.5539/elt.v9n3p117

Mudra, H. (2018). Metacognitive online reading strategies among pre-service EFL teachers in Indonesia. Educational Process: International Journal, 7(2), 151-164.

doi: 10.22521/edupij.2018.72.5

Oh, E. J. (2016). Relationships among perceived self-efficacy, vocabulary and grammar knowledge, and L2 reading proficiency. English Teaching, 71(2), 3-29. doi: 10.15858/engtea.71.2.201606.3

Osman, M. E. T., Al Khamisi, H., Al Barwani, T., \& Al Mekhlafi, A. (2016). EFL reading achievement: Impact of gender and self-efficacy beliefs. International Journal of Learning, Teaching and Educational Research, 15(3), 54-73.

Phan, H. P. (2012). The development of English and mathematics self-efficacy: A latent growth curve analysis. The Journal of Educational Research, 105(3), 196-209. https://doi.org/10.1080/00220671.2011.552132

Phan, H. P., \& Ngu, B. H. (2016). Sources of self-efficacy in academic contexts: A longitudinal perspective. School Psychology Quarterly, 31(4), 548-564.

Rahman, M. M., \& Alhaisoni, E. (2013). Teaching English in Saudi Arabia: Prospects and challenges. Academic Research International, 4(1), 112-118.

Razek, N., \& Coyner, S. C. (2014). Impact of self-efficacy on Saudi students' college performance. Academy of Educational Leadership Journal, 18(4), 85-96.

Ruegg, R., Naganuma, N., (2019). Development of reading skills in an EAP Programme: A longitudinal study. The Asian ESP Journal, 15(1.1), 39-61.

Saleem, M., Ali, M., \& Ab Rashid, R. (2018). Saudi students' perceived self-efficacy and its relationship to their achievement in English language proficiency. Arab World English Journal, 9(2), 397-413. http://dx.doi.org/10.2139/ssrn.3201927

Schöber, C., Schütte, K., Köller, O., McElvany, N., \& Gebauer, M. M. (2018). Reciprocal effects between self-efficacy and achievement in mathematics and reading. Learning and Individual Differences, 63(1), 1-11. https://doi.org/10.1016/j.lindif.2018.01.008 
Shang, H. F. (2010). Reading strategy use, self-efficacy and EFL reading comprehension. Asian EFL Journal, 12(2), 18-42.

Shehzad, M.W., Alghorbany, A., Lashari, S.A., Lashari, T.A., Razzaq, S. (2019). The interplay between pronunciation self-efficacy sources and self-efficacy beliefs: A structural equation modeling approach. Indonesian Journal of Applied Linguistics, 9(1), 177-187.

Shehzad, M.W., Hamzah, H., Rawian, R.M. (2018). The relationship of self-efficacy sources and metacognitive reading strategies: Mediating role of reading self-efficacy beliefs. Pakistan Journal of Humanities and Social Sciences, 6(1), 99-120.

Tabrizi, A. R. N., \& Jafari, M. (2015). The relationship among critical thinking, self-efficacy, and Iranian EFL learners' reading comprehension ability with different proficiency levels. Academic Research International, 6(2), 412.

Taylor, B. M., Pearson, P. D., Clark, K., \& Walpole, S. (2000). Effective schools and accomplished teachers: Lessons about primary-grade reading instruction in low-income schools. The Elementary School Journal, 101(2), 121-165.

Teba, S. C. (2017). Using effective strategies for errors correction in EFL Classes: A case study of secondary public schools in Benin. Journal of Education and e-Learning Research, 4(2), 63-71.

Thomas, R. M. (2003). Blending qualitative and quantitative research methods in theses and dissertations. Thousand Oaks, CA: Corwin Press.

Tschannen-Moran, M., \& McMaster, P. (2009). Sources of self-efficacy: Four professional development formats and their relationship to self-efficacy and implementation of a new teaching strategy. The Elementary School Journal, 110(2), 228-245. https://www.jstor.org/stable/10.1086/605771

Unrau, N. J., Rueda, R., Son, E., Polanin, J. R., Lundeen, R. J., \& Muraszewski, A. K. (2018). Can reading self-efficacy be modified? A meta-analysis of the impact of interventions on reading self$\begin{array}{llll}\text { efficacy. Review of } & \text { Educational } & \text { Research, 88(2), } & \text { 167-204. }\end{array}$ https://doi.org/10.3102/0034654317743199

Usher, E. L. (2009). Sources of middle school students' self-efficacy in mathematics: A qualitative investigation. American Educational Research Journal, 46(1), 275-314. https://doi.org/10.3102/0002831208324517

Usher, E. L., \& Pajares, F. (2009). Sources of self-efficacy in mathematics: A validation study. Contemporary Educational Psychology, 34(1), 89-101. https://doi.org/10.1016/j.cedpsych.2008.09.002

Wilson, A., \& Kim, W. (2016). The effects of concept mapping and academic self-efficacy on mastery goals and reading comprehension achievement. International Education Studies, 9(3), 12-23. http://dx.doi.org/10.5539/ies.v9n3p12

Yoğurtçu, K. (2013). The impact of self-efficacy perception on reading comprehension on academic achievement. Procedia-Social and Behavioral Sciences, 70(1), 375-386. https://doi.org/10.1016/j.sbspro.2013.01.075

\section{AUTHOR BIODATA}

Dr. Mohammed Abdullah Alharbi is an associate professor in the Department of English at Majmaah University, Saudi Arabia. His research interests include L2 writing instruction, computer-mediated communication, peer review, and peer feedback. 